\title{
Design and technological parameters of equipment influence on the lateral pressure coefficient and reduced friction coefficient of granular polyvinyl chloride
}

\author{
Viktor Vytvytskyi ${ }^{1}$, Ihor Mikulionok ${ }^{1}$, Oleksandr Sokolskyi ${ }^{1}$, \\ Oleksandr Gavva², Liudmyla Kryvoplias-Volodina²
}

\section{1 - National Technical University of Ukraine "Igor Sikorsky Kyiv Polytechnic Institute", Kyiv, Ukraine 2 - National University of Food Technologies, Kyiv, Ukraine}

\section{Keywords:}

Bulk

Polymer

Granule

Lateral pressure

Friction

Article history:

Received

21.04.2020

Received in

revised form

29.09.2020

Accepted

25.03.2021

Corresponding

author:

Oleksandr Gavva

E-mail:

gavvaoleksandr@ gmail.com

\section{DOI:}

10.24263/2304-

974X-2021-10-1-

16

\section{Abstract}

Introduction. The dependence of the lateral pressure coefficient and the reduced friction coefficient of granular polyvinyl chloride was determined for the production of packaging material from the design and technological parameters of the feeding process.

Materials and methods. Experiments has been carried out on the stand which simulating the movement of polymer granules in the working channel of a single-screw extruder for such parameters: the polymer being researched - polyvinyl chloride (PVC); the axial pressure - 0.044$0.475 \mathrm{MPa}$; the temperature of the steel limiting surface $-20-80^{\circ} \mathrm{C}$; the speed of the steel limiting surface $-0.176-0.471 \mathrm{~m} / \mathrm{s}$; the height of the granular polymer layer $-0.015-0.025 \mathrm{~m}$.

Results and discussion. The value of the lateral pressure coefficient increases under the following conditions: temperature increase; reduction of axial pressure; speed reduction; the lateral pressure coefficient does not depend on the height of the granules layer. Provided simultaneous changes in temperature and pressure to a level of approximately $0.32 \mathrm{MPa}$ increase in temperature leads to increased values of lateral pressure, after it - on the contrary, to reduce. In case of speed change after point 0.15 $\mathrm{MPa}$ dependence also reversed.

Most on the growth of the lateral pressure coefficient of the studied polymer affects the simultaneous action of the temperature and the speed of the steel limiting surface. The central role in changing the lateral pressure coefficient is having by speed, and in changing the friction coefficient have by temperature.

In the case of simultaneous temperature rise with the speed and the layer of granules height there is a transition through the point at the level of approximately $0.32 \mathrm{MPa}$. To this point, an increase in temperature leads to an increasing in the corresponding values of the lateral pressure coefficient. After this point on the contrary - to decreasing in the corresponding values of the lateral pressure coefficient. The same in case of speed change, after the point $0.15 \mathrm{MPa}$ the dependence is reversed.

In the case of simultaneous rise the speed and the temperature from 20 to $80{ }^{\circ} \mathrm{C}$ the larger values of speed correspond to the smaller values of lateral pressure coefficients. The increase in temperature leads to an increase in the lateral pressure coefficients from $0.33-0.34$ to $0.42-0.46$.

In the case of simultaneous rise the speed and the pressure the lower pressure values do not affect the dependence of the values of the lateral pressure coefficient on the speed. An increase in pressure from 0.044 to $0.476 \mathrm{MPa}$ leads to corresponding change to increasing dependence from $0.22-0.27$ to $0.34-0.46$.

Subject to change in temperature, speed and granule layer height an increase in temperature leads to a corresponding increase values of the friction coefficient at the same pressure from $0.48-0.5$ to $0.52-0.57$ as well as increasing speed.

Conclusions. The obtained results make it possible to take into account the mutual influence of the friction and the lateral pressure coefficients of the granular polymers and the design and technological parameters of the extruder or screw feeder. 


\section{Introduction}

One of the most versatile and productive methods of processing polymers into a variety of products is extrusion [1-4]. In particular, packaging materials such as polymer films and sheets are obtained by extrusion [5-8]. Polymeric raw materials intended for further processing are obtained, stored and supplied to the consumer in the form of granules of various shapes (cylindrical, cubic, spherical, elliptical, etc.) with an equivalent diameter mostly within 3-6 mm [9].

The process of screw extruder feeding with granular polymer raw material materials determines the course of all processes occurring in the following functional zones of the extruder [2]. It is in the supply zone that the pressure required for further movement of the polymer through other zones of the extruder and the extrusion head is generated. In turn, this affects the quality of the products, in particular on the stability of the thickness of the polymer films, which are widely used for packaging food, chemical and other products.

Effective treatment of granular polymers presupposes the availability of information on its physical and mechanical properties, including the friction coefficients on different surfaces, as well as the lateral pressure coefficient [10].

Extensive research carried out for thermal properties (including true density) the most common heavy-duty polymers and plastics, as well as their friction coefficient on the steel surface [11-13].

The study of external friction coefficients for polymeric materials with characteristic of modern brands specification was also carried out. However, these studies were conducted mainly for monolithic material which does not allow to use the obtained data to analyze the behavior of polymer granules [14-15]. Also conducted studies of tribological properties of granular polymers [16-17], however, they all relate to the determination of the reduced friction coefficient of the polymer granules on the limiting surface.

As you can see, if for granular polymers were studied certain physical and mechanical properties, but the data relative to the coefficient of lateral pressure, which significantly affects the accuracy of equipment design [18], almost completely absent even for the most common polymers.

The coefficient of lateral pressure $\mathrm{K}_{\mathrm{LP}}$ takes into account the anisotropy of the pressure and is numerically equal to the ratio of the pressure on the side surfaces to the axial pressure. It is traditionally assumed that in static conditions the value of $\mathrm{K}_{\mathrm{LP}}$ is of the order of $0.3-0.4$, and in dynamic conditions (when the screw rotates) the value of $\mathrm{K}_{\mathrm{LP}}$ increases to unity [1924]. However, the operation of industrial equipment indicates [23] that the value of $\mathrm{K}_{\mathrm{LP}}$ for different materials can differ essentially and depend on design and technological parameters of the equipment for treatment or processing of granules.

In view of the above, the task of a comprehensive study of the dependence of the friction coefficient and of the lateral pressure coefficient of the most commonly used granular polymers on the design and technological parameters of the equipment.

The objective of the work is establishing the dependence of such tribotechnical characteristics of granular polyvinyl chloride (PVC), as the lateral pressure coefficient and the reduced friction coefficient from design and technological parameters the process of feeding granular material, in particular the axial pressure, temperature and speed of the steel limiting surface, as well as the height of the layer of granules. 


\section{Materials and methods}

\section{Materials}

Polyvinyl chloride granules (PVC) SorVyl G 2171/9005 11/01 [25] were selected for research. Polyvinyl chloride has been selected for research due to its widespread use in the packaging industry, in particular in the manufacture of packaging films and bottles of household chemicals.

\section{Experimental installation}

The designed experimental installation [26] makes it possible to researched the values of the external friction coefficient and the lateral pressure coefficient of granular materials on different surfaces, including depending on temperature, load, speed of a rotor rotation and a layer of granules height in a wide range of values.

Installation (Figure 1) consists of rotor 3, heaters 2 and vertical box 4, which is made hollow and mounted above the rotor. In the box placed pusher 5, which receiving the load through the regulator of the vertical force 6 . Also in the box placed sensors of horizontal forces 11 and 13 .

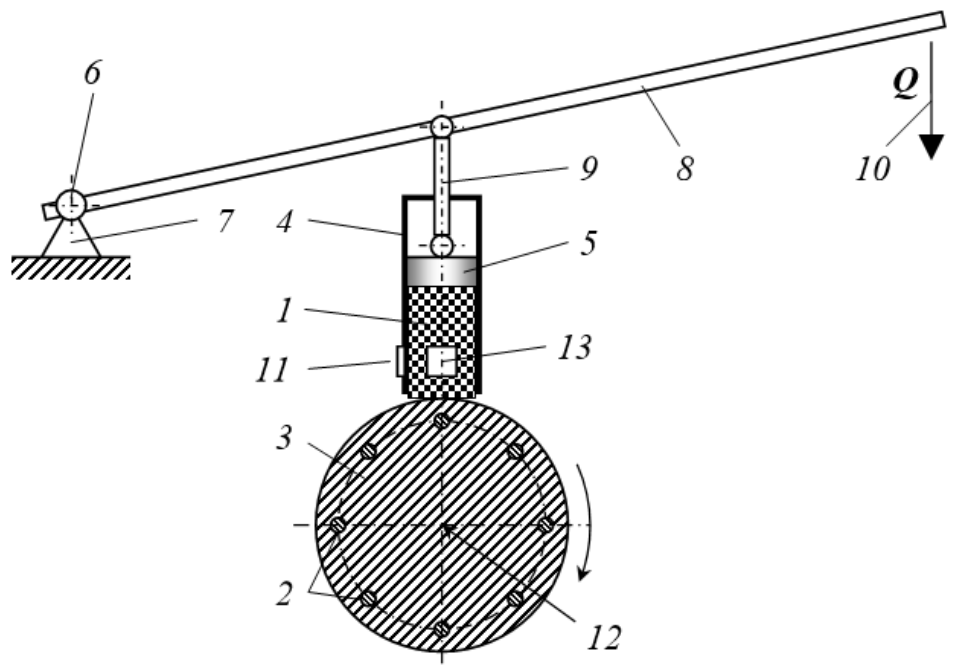

Figure 1. Scheme of an experimental installation: $Q$ - load on the rod;

1 - installation; 2 - heaters; 3 - rotor; 4 - box; 5 - pusher; 6 - regulator of the vertical force; 7 - riser; 8 - lever; 9 - stock; 10 - counterweight; 11 - horizontal force sensor; 12 - the axis of the rotor; 13 - horizontal force sensor

The principle of operation of the installation is as follows: the granules are filled into a vertical box and pressed by the rod to the rotor, which is given the rotation of the motor. The sensor installed in the course of rotation of the rotor makes it possible to obtain the value of the friction coefficient, and the second sensor installed perpendicular to the first makes it possible to obtain the value of the lateral pressure coefficient. 
By changing the speed of the rotor rotation, the temperature of the heaters or the load on the rod $Q$ - you can get the above dependences for the desired coefficients.

\section{Research methods}

The planning of experimental researches was based on the method of a complete factorial experiment [27], which is based on a method of constructing the dependence of the determining factors influence on the optimization parameter in the form of a segment of the Taylor power series.

The optimization parameter $\mathrm{K}_{\mathrm{LP}}$ (lateral pressure) will be affected by the following factors:

1. Linear speed of the rotor rotation $(v)$;

2. Rotor temperature $(t)$;

3. Pressure on the material $(p)$;

4. Working channel height $(h)$.

Given the design and technological parameters of the extrusion process for these factors, the following ranges of their change were selected:

1. Linear speed of the rotor rotation $v=0,176-0,471 \mathrm{~m} / \mathrm{s}$;

2. Rotor temperature $t=20-80{ }^{\circ} \mathrm{c}$;

3. Pressure on the material $p=0,044-0,476 \mathrm{mpa}$;

4. Working channel height $h=15-25 \mathrm{~mm}$.

The results are processed according to a known algorithm [27].

The error in obtaining experimental values does not exceed $10.5 \%$ according to Fisher's criterion.

\section{Results and discussion}

\section{Features of polymeric materials processing in single-screw extruders}

As the material moves along the screw channel of a single-screw extruder, it successively changes several states: from solid at the inlet to the channel to viscous at the outlet. This channel is traditionally divided into three functional zones: feeding, melting and homogenization (Figure 2). The efficiency of screw machines is primarily determined by the processes that take place in the first two zones, as the share of power consumed here reaches $80 \%$ of the power consumed by the extruder. The productivity of the feeding zone determines the productivity of the process as a whole.

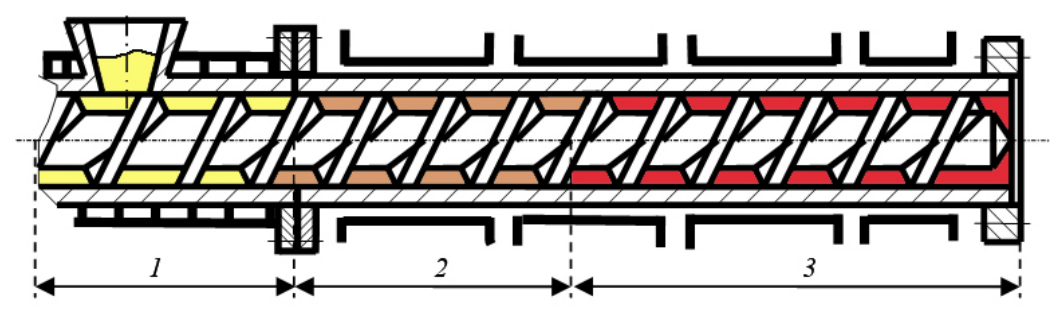

Figure 2. Scheme of one-screw extruder:

1 - feeding zone, 2 - melting zone, 3 - homogenization zone 
The curves of the dependence of the specific productivity $G_{n}$ on the ratio of the coefficients of friction of the polymer granules on the surfaces of the cylinder and the worm $F=f_{\mathrm{c}} / f_{\mathrm{s}}$ are shown in Figure 3 . The specific productivity significantly depends on this ratio at its small values, and in the case of increasing the value of $F$, this dependence decreases and asymptotically goes to a certain value [28].

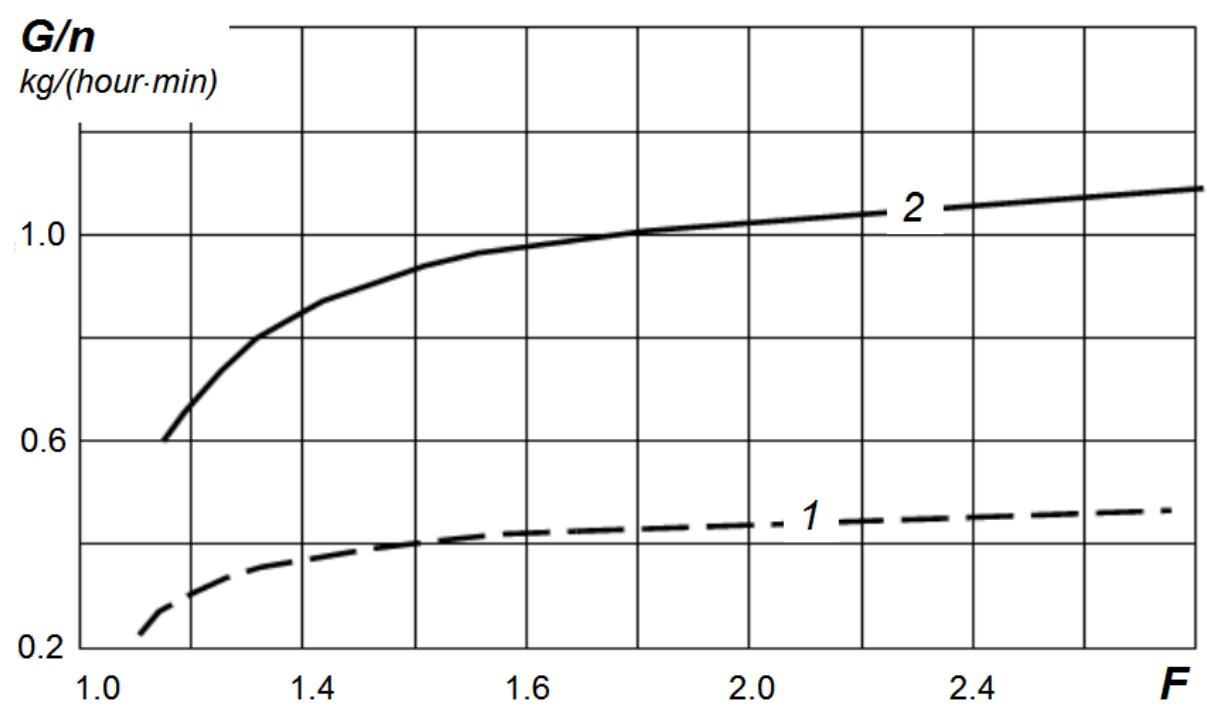

Figure 3. Curves of dependence of specific productivity on the ratio of friction coefficients:

$1-D=45 \mathrm{~mm} ; H=4 \mathrm{~mm}$;

$2-D=63 \mathrm{~mm} ; H=5 \mathrm{~mm}$

The productivity of the feeding zone is [28]

$$
G=\rho_{0}\left\{\frac{\pi}{4}\left[D^{2}-(D-2 H)^{2}\right]-\frac{E H}{\operatorname{tg} \varphi}\right\} \pi D n \frac{\operatorname{tg} \omega \operatorname{tg} \varphi}{\operatorname{tg} \omega+\operatorname{tg} \varphi} .
$$

The increase in pressure from $P_{1}$ to $P_{2}$ in the selected element of the length of the feeding zone is determined by dependence

$$
P_{2}=P_{1} \exp \left(\frac{\pi D f_{c} K_{\mathrm{LP}} \Delta L}{b H} A\right)
$$

where

$$
A=\cos (\omega+\varphi)-f_{\mathrm{s}} \sin (\omega+\varphi)-\frac{f_{\mathrm{c}}}{f_{\mathrm{s}}} \frac{(D-2 H)}{D}
$$


In the above dependencies $\rho_{o}$ - polymer bulk density, $\mathrm{kg} / \mathrm{m}^{3} ; D$ - screw diameter, $\mathrm{m}$; $H$ - channel depth (thread), $\mathrm{m} ; E$ - ridge width, $\mathrm{m} ; n$ - frequency, $\mathrm{s}^{-1} ; \omega$ and $\varphi-$ angles determined by the direction of the speed vector of the polymer; $f_{\mathrm{c}}, f_{\mathrm{s}}-$ the friction coefficient of the polymer against the cylinder and the screw, respectively; $b=(S-E) \cos \varphi-$ screw channel width, $\mathrm{m} ; K_{\mathrm{LP}}-$ lateral pressure coefficient.

Therefore, taking into account the peculiarities of the mutual influence of structural and technological parameters of the equipment, coefficients of friction and of lateral pressure allows to clarify the results of worm extruders and screw feeders calculations.

It is established that the central role in changing the lateral pressure coefficient plays by speed, and in changing the friction coefficient plays by temperature. The mutual influence of the third order parameters is insignificant and these components can be neglected.

Using the above regression equations, graphical dependences of the coefficients of friction and of lateral pressure of the considered material on the variable parameters were obtained.

\section{Research of the lateral pressure coefficient}

For each polymer, the parameters not listed below the graphs are equal to the smallest value in the range of the complete factorial experiment for the corresponding material.

From those shown in Figure 4-5 dependences of the lateral pressure coefficient on the pressure when the temperature, speed and height of the granules layer change, the general decreasing character of these dependences is noticeable. In the case of simultaneous temperature rise with the speed and the layer of granules height (see Figure 5) there is a transition through the point at the level of approximately $0.32 \mathrm{MPa}$. To this point, an increase in temperature leads to an increasing in the corresponding values of the lateral pressure coefficient. After this point on the contrary - to decreasing in the corresponding values of the lateral pressure coefficient. The same in case of speed change, after the point $0.15 \mathrm{MPa}$ the dependence is reversed, that is, to a certain value of pressure, a simultaneous increase in speed leads to a decrease in the corresponding values of the lateral pressure coefficient, and after reaching this value - on the contrary, to increasing.

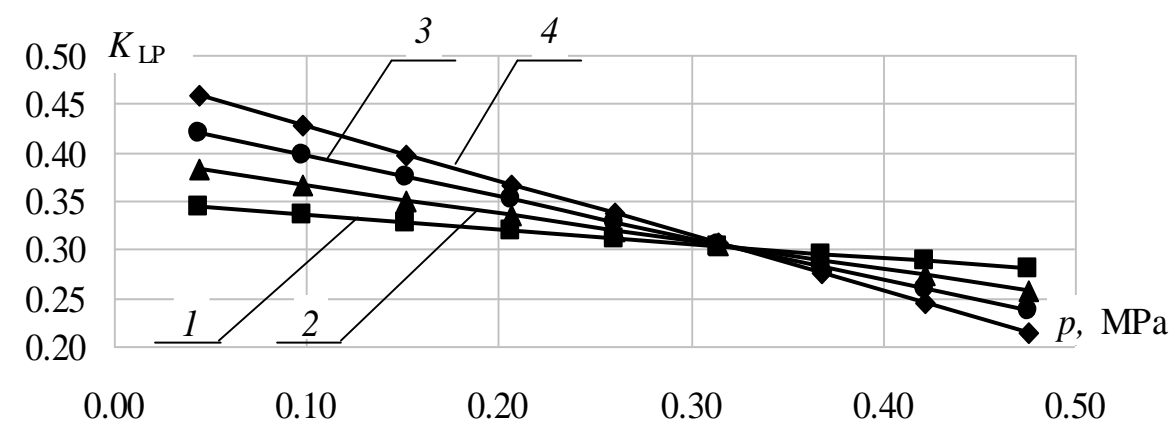
Figure 4. Dependence of the PVC lateral pressure coefficient on the pressure at different temperatures,

${ }^{\circ} \mathrm{C}: 1$ - 20; $2-40 ; 3-60 ; 4-80$ 


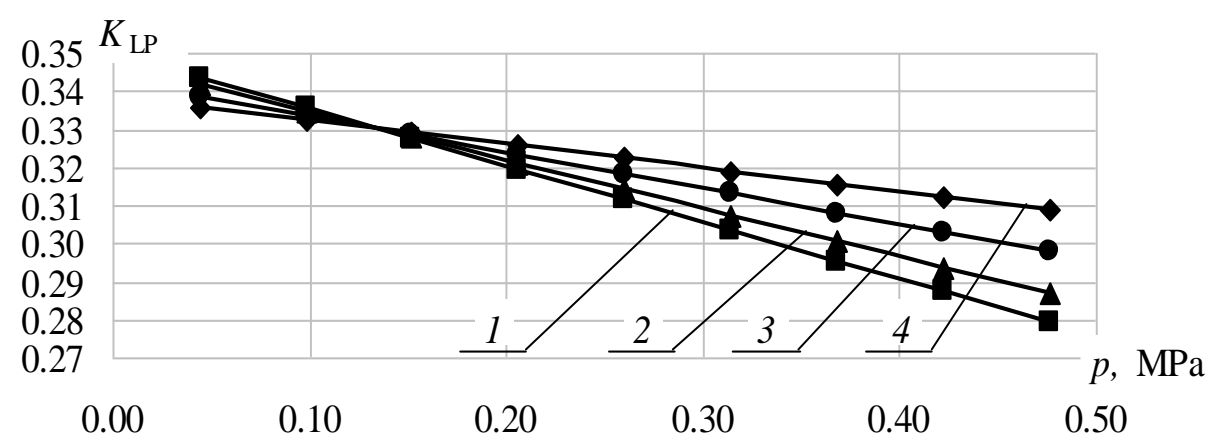

Figure 5. Dependence of the PVC lateral pressure coefficient on the pressure at different speeds, $\mathbf{m} / \mathbf{s}$ :

$$
1-0.176 ; 2-0.244 ; 3-0.346 ; 4-0.448
$$

Such changes, in our opinion, can be explained by the beginning of the angular deformation of the granules during movement while softening the material.

In Figure 6-7 shown dependences of the lateral pressure coefficient on the speed when the temperature, pressure and height of the granules layer change. Thus, while increasing the temperature and speed (see Figure 6) larger values of speed correspond to smaller values of lateral pressure coefficient and the temperature rise (see. Figure 7) increases the lateral pressure coefficients. At simultaneous action of speed and pressure, smaller values of pressure do not influence dependence of values lateral pressure coefficient on speed, but pressure increase leads to the corresponding change to the increasing dependence.

These results can be explained by the compaction of the granule layer after compression and its transformation from bulk to a solid medium.

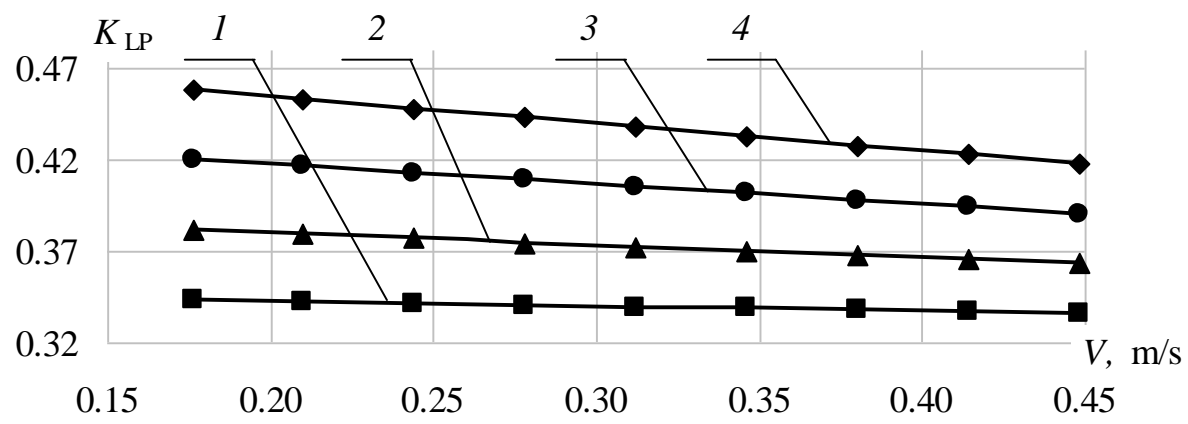

Figure 6. Dependence of the PVC lateral pressure coefficient on the speed at different temperatures, ${ }^{\circ} \mathrm{C}$ :

$1-20 ; 2-40 ; 3-60 ; 4-80$ 


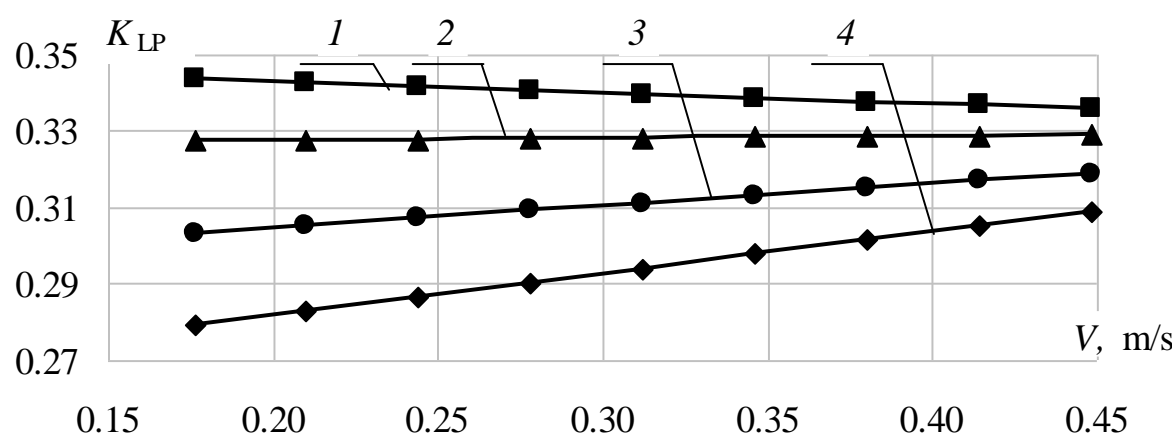

Figure 7. Dependence of the PVC lateral pressure coefficient on the speed at different pressure, MPa:

$$
1-0.044 ; 2-0.152 ; 3-0.314 ; 4-0.476
$$

In Figure 8-9 show the change of the lateral pressure coefficient from the temperature when the speed, pressure and height of the granules layer change. At the same time the general growing character of these dependences is appreciable. With at additional increase in speed (see Figure 8) there is a slight decrease in the corresponding lateral pressure coefficient, just like that with increasing pressure (see Figure 9), and the change in the height of the granules layer does not affect the dependence of the lateral pressure coefficient on the pressure.

These results can be explained by the softening of the layer of granules from temperatures and stresses that go beyond the region of elasticity of the material.

The dependences of the lateral pressure coefficient on the height of the granules layer when the speed, temperature and pressure change were also researched [18]. It is established that the increase in pressure leads to a decrease in the corresponding values of the lateral pressure coefficient as well as increasing the speed. At the same increase in temperature leads to an increase in the corresponding values of the lateral pressure coefficient.

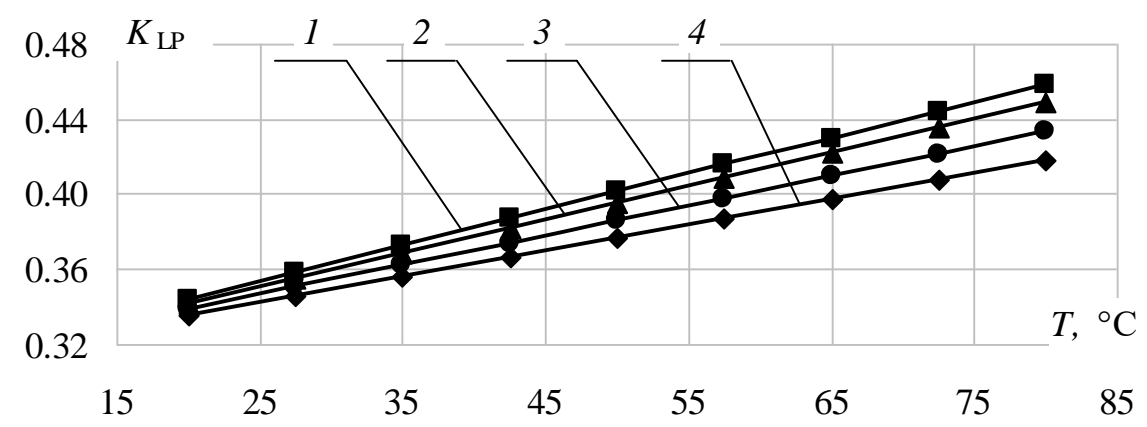

Figure 8. Dependence of the PVC lateral pressure coefficient on the temperature at different speeds, $\mathbf{m} / \mathbf{s}$ :

$1-0.176 ; 2-0.244 ; 3-0.346 ; 4-0.448$ 


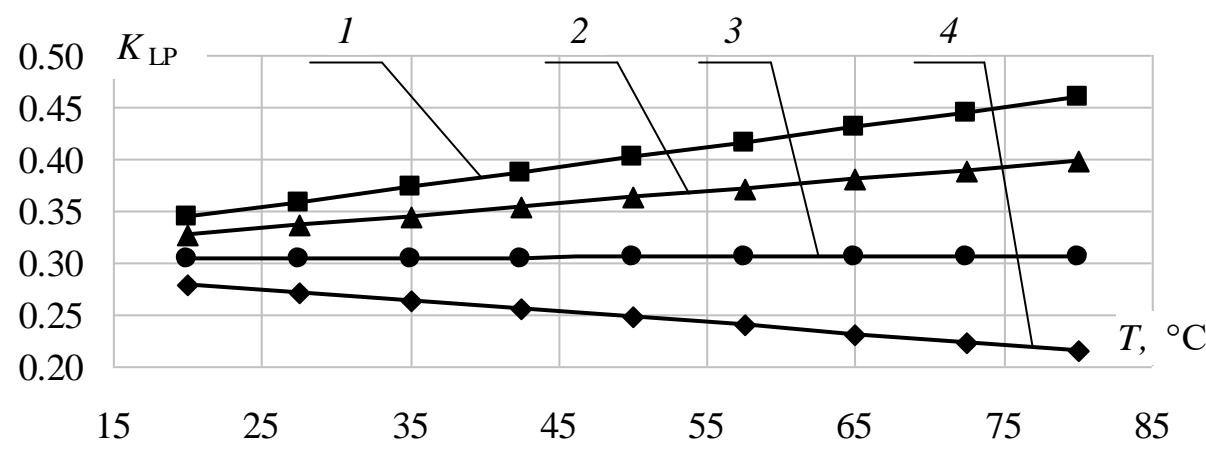

Figure 9. Dependence of the PVC lateral pressure coefficient on the temperature at different pressure, MPa:

$1-0.044 ; 2-0.152 ; 3-0.314 ; 4-0.476$

\section{Research of the friction coefficient}

In Figure 10-17 show the graphical dependences of the values of the reduced PVC friction coefficient on the steel surface from the structural and technological parameters of the extrusion process.

Parameters not listed below the graphs are the lowest values in the full factorial experiment range.

From shown in Figure 10-12 dependences, a slight decrease in the reduced coefficient of friction from pressure is noticeable subject to change in temperature, speed and height of the granules layer. The increase in temperature (see Figure 10) leads to a corresponding increase in the values of the friction coefficient at the same pressure, as well as an increase in speed (see Figure 11), and the height of the granules layer (see Figure 12) has almost no effect on the corresponding change in the coefficient of friction, except for high values of pressure.

The latter can be explained by the fact that with a larger layer of granules, the increase in pressure leads to their compaction and movement as a solid body, when the effect of rolling the granules one by one disappears, that is reducing the effect of rolling friction.

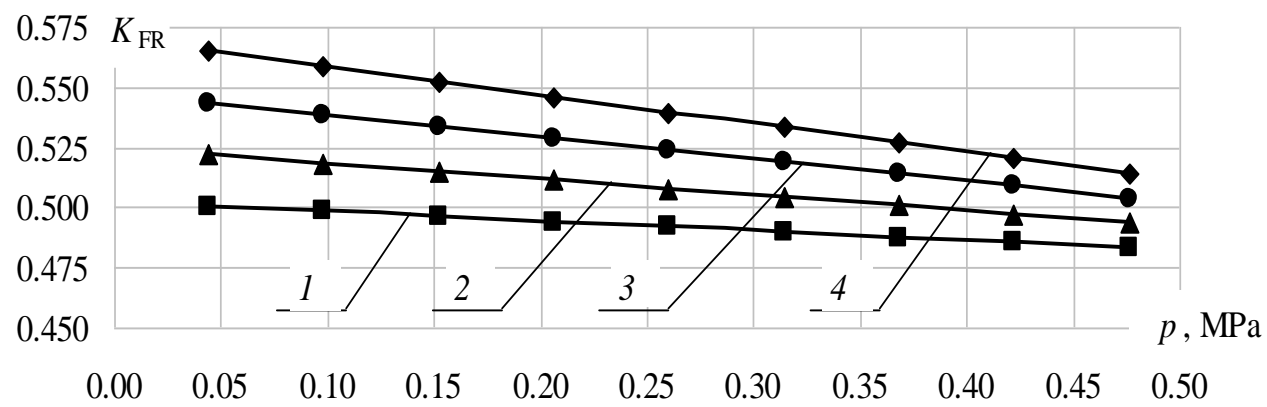

Figure 10. Dependence of the PVC friction coefficient on the pressure at different temperatures, ${ }^{\circ} \mathrm{C}$ :

$1-20 ; 2-40 ; 3-60 ; 4-80$ 


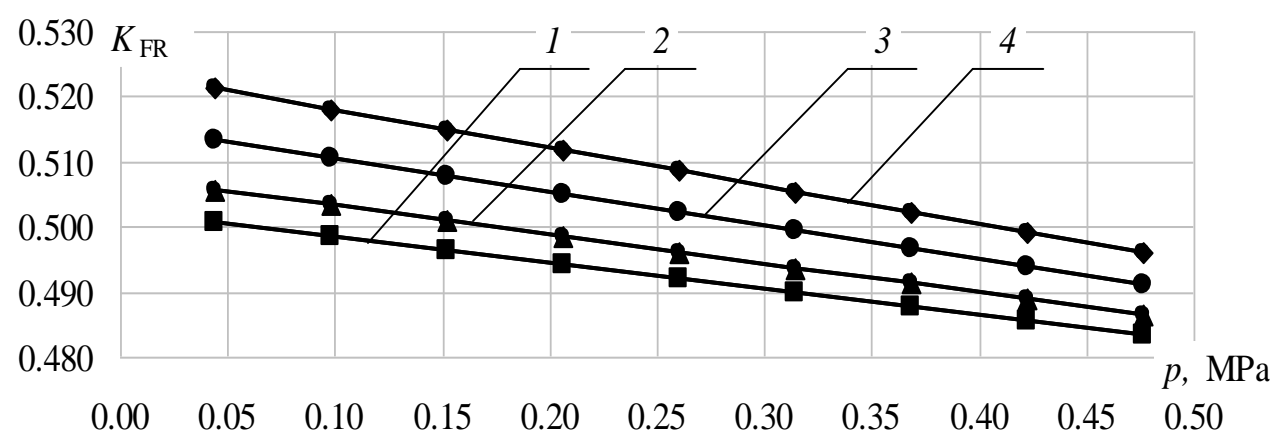

Figure 11. Dependence of the PVC friction coefficient on the pressure at different speeds, $\mathrm{m} / \mathrm{s}$ : 1 - 0,176; 2 - 0,244; 3 - 0,346; 4 - 0,448

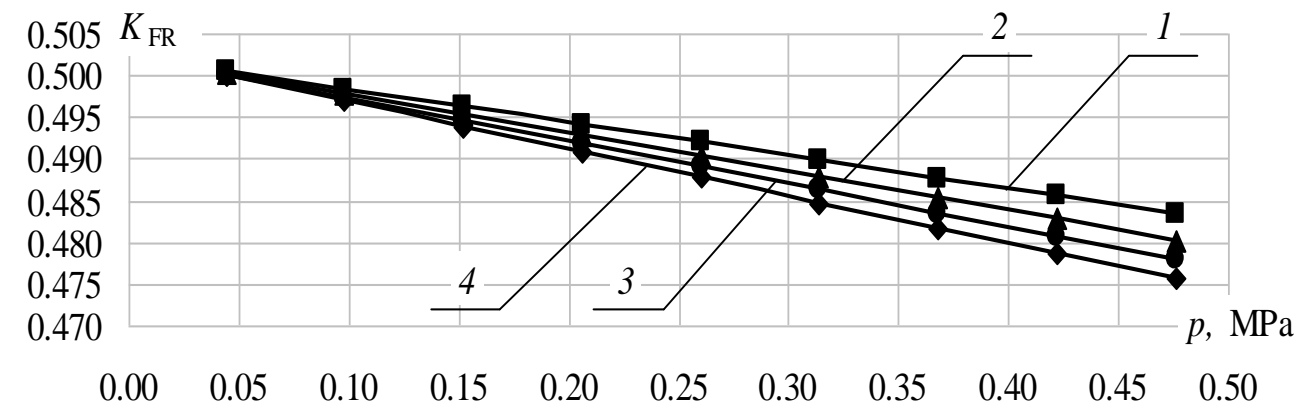

Figure 12. Dependence of the PVC friction coefficient on the pressure at different heights of the granules layer, $\mathbf{m}$ :

$1-0,015 ; 2-0,019$;

$3-0,022 ; 4-0,025$

From dependencies shown in Figure 13-14 a slight increase in the reduced friction coefficient from the speed of the limiting surface is noticeable under the condition of change the temperature, pressure and height of the granules layer. An increase in temperature (see Figure 13) leads to an increase in the corresponding values of the friction coefficient and increase in pressure (see Figure 14) on the contrary, leads to a decrease in the corresponding values of the friction coefficient. 


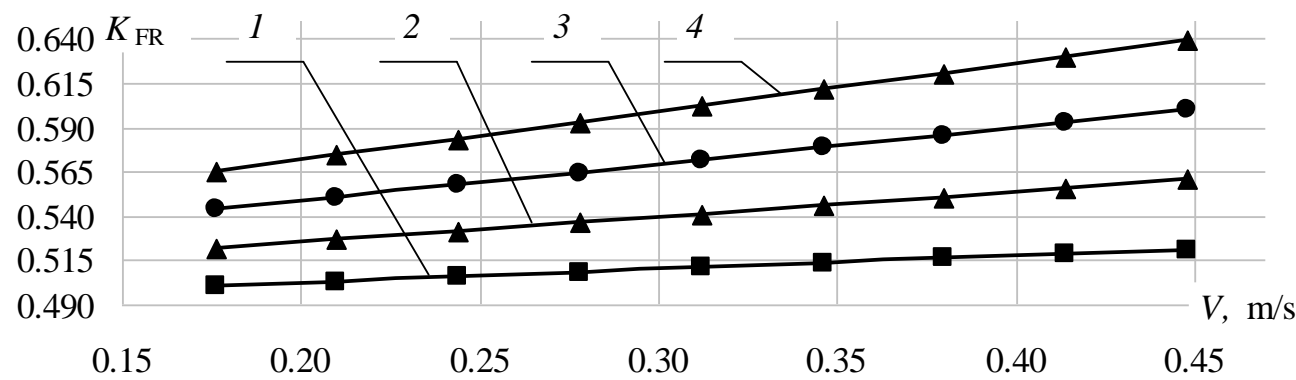

Figure 13. Dependence of the PVC friction coefficient on the speed at different temperatures, ${ }^{\circ} \mathrm{C}$ :

$1-20 ; 2-40 ; 3-60 ; 4-80$

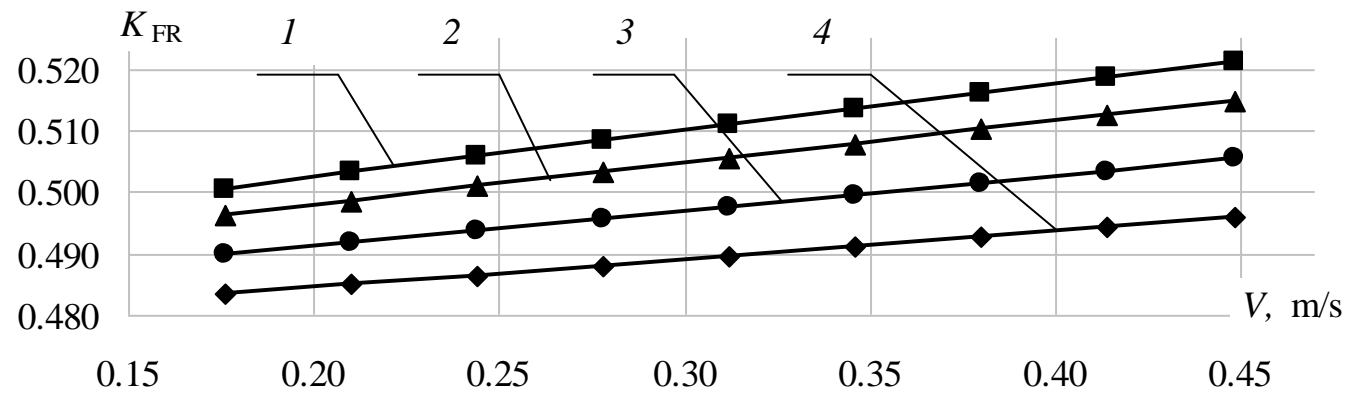

Figure 14. Dependence of the PVC friction coefficient on the speed at different pressure, MPa: $1-0,044 ; 2-0,152 ; 3-0,314 ; 4-0,476$

These dependences can be explained by the fact that increasing the temperature increases the forces of interaction of the polymer with the surface, and increasing the pressure leads to smoothing of the surfaces of the granules.

From dependencies shown in Figure 15-16, a slight increase in the reduced coefficient of friction with temperature is noticeable under the condition of change of speed of a limiting surface, pressure and height of the granules layer. In general, the reduced friction coefficient increases with increasing temperature. In this case, increasing the speed of the limiting surface (see Figure 15) leads to an increase in the values of the friction coefficient and increasing in pressure (see Figure 16) on the contrary, leads to a decrease in the values of the friction coefficient. 


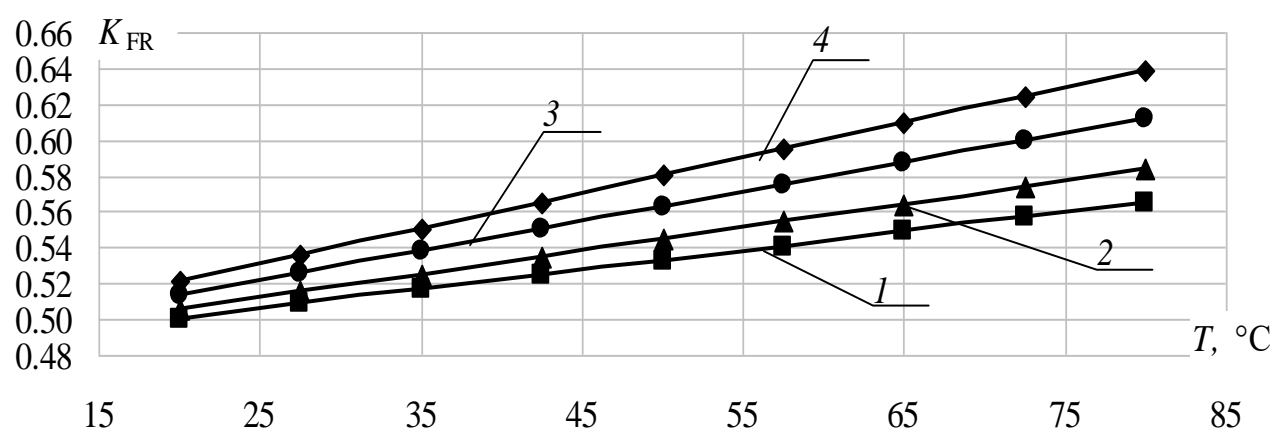

Figure 15. Dependence of the PVC friction coefficient on the temperature at different speeds, $\mathrm{m} / \mathrm{s}: 1$ - 0,176; 2 - 0,244; 3 - 0,346; 4 - 0,448

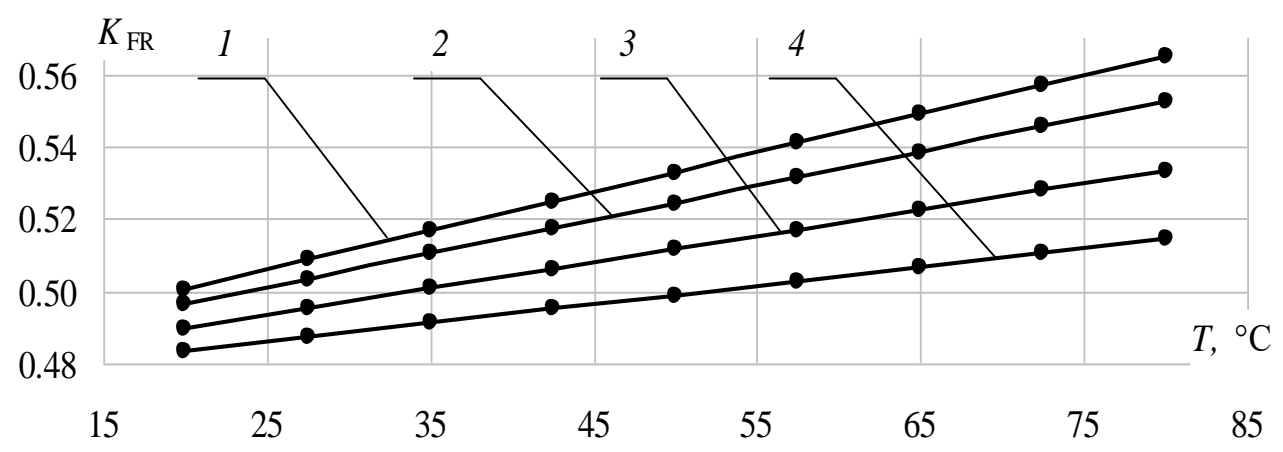

Figure 16. Dependence of the PVC friction coefficient on the temperature at different pressure, MPa: 1 - 0,044; 2 - 0,152; 3-0,314; 4 - 0,476

These dependences can be explained by the fact that increasing the temperature increases the forces of interaction of the polymer with the surface, and increasing the speed and pressure leads to the compaction of the surface layer of the polymer.

In Figure 17 shows the dependence of the value of the reduced friction coefficient on the height of the granules layer under the condition of pressure change. The influence of the speed of the limiting surface and temperature the reduced coefficient of friction is almost absent and the increase in pressure (see Figure 17) leads to a slight decrease in the reduced coefficient of friction. 


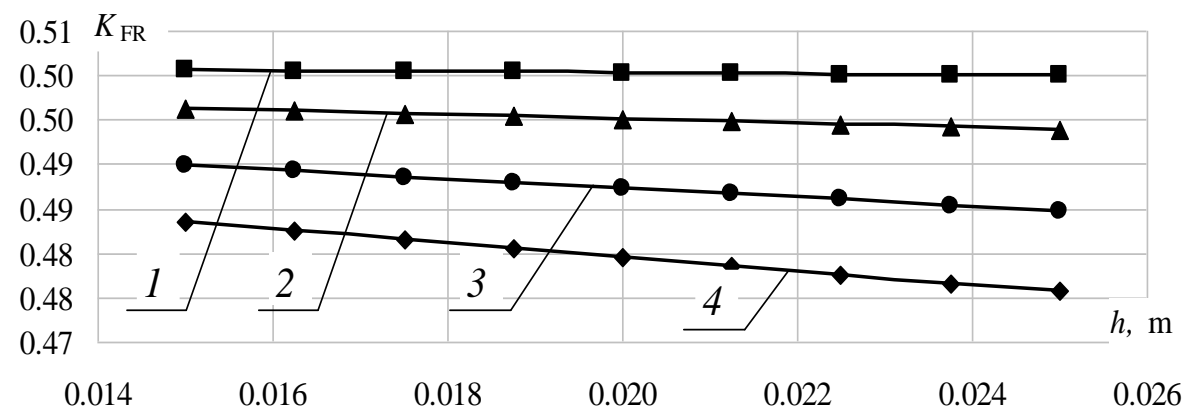

Figure 17. Dependence of the PVC friction coefficient on the height of the granules layer at different pressure, MPa: 1 - 0,044; 2 - 0,152; 3-0,314; 4 - 0,476

These dependences, in our opinion, can be explained by the fact that increasing the height of the granules layer of reduces the pressure transfer to the friction surface.

To verify the obtained experimental data, calculations of the process of feeding the screw extruder with polymer raw materials were performed with the initial data of the available experimental research of the authors [29] and compared the results, obtained taking into account the researched dependences of the friction coefficient and lateral pressure coefficient with their constant values (Figure 18).

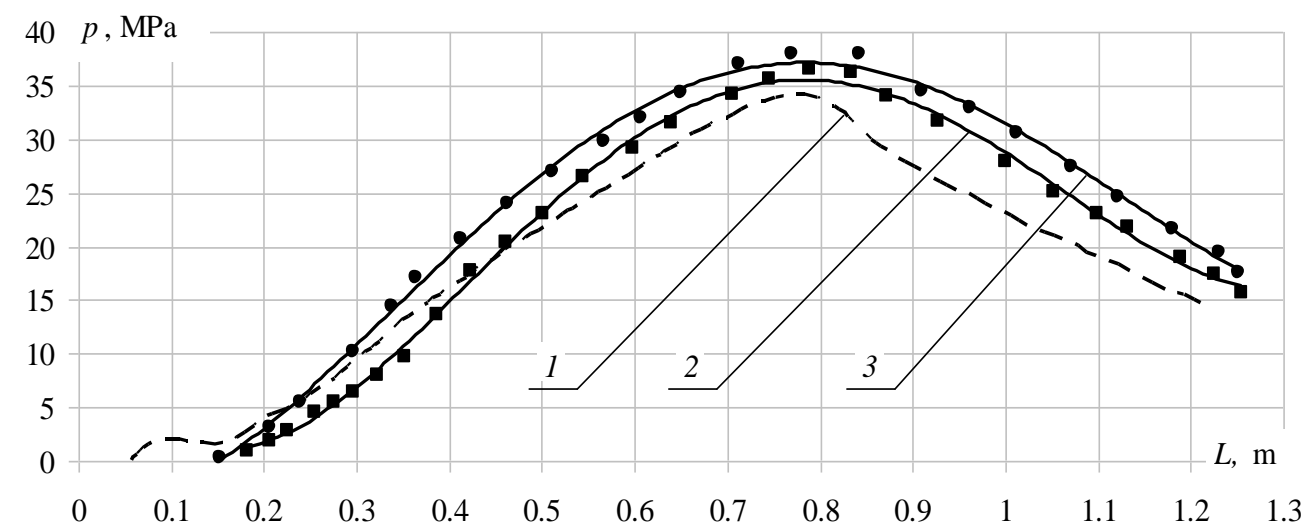

Figure 18. Pressure distribution along the extruder length:

1 - experimental data; 2 - calculation taking into account the researched dependencies; 3 - calculation at constant values of coefficients

From Figure 18 it is seen that the calculation taking into account the change of the coefficients gives the pressure values along the length of the extruder closer to the experimental values than the base, almost the entire length. In this case, in comparison with the experimental data, the maximum discrepancy of the values obtained in the basic calculation is $32 \%$ and in the proposed method is $18 \%$ (on the length interval $L=1 \mathrm{~m}$ ). 
The obtained results make it possible to take into account the mutual influence of the friction coefficient and of the lateral pressure coefficient (together with other physical and mechanical properties of the processed polymeric material) and design and technological parameters of the equipment (including the seeding zone of the screw extruder and the working channel of the screw feeder), and therefore in the case of development and modernization of technological and ancillary equipment for processing and treatment of granular polymers make it possible to determine the rational values of design and technological parameters of the appropriate equipment.

\section{Conclusion}

The following conclusions can be drawn, based on the obtained results:

1. The dependence of the reduced friction coefficient of granular polyvinyl chloride on the steel surface on the pressure (load) acting on the layer of granular polymer is determined. The decrease in the friction coefficient from the load at different values of other parameters (temperature, speed and height of the granules layer) is shown. An increase in the friction coefficient from temperature and speed, as well as a decrease from the height of the layer of granules under a certain load is proved.

2. The dependence of the reduced friction coefficient of granular polyvinyl chloride on the steel surface on the speed of the limiting steel surface is determined. The increase of the friction coefficient from speed at different values of other parameters (temperature, pressure and height of the granules layer) is shown. An increase in the friction coefficient from temperature and a decrease from pressure, as well as the absence of dependence on the height of the granules layer at a certain speed are proved.

3. The dependence of the reduced friction coefficient of granular polyvinyl chloride on the steel surface on the temperature of the limiting steel surface is determined. The increase of the friction coefficient from temperature at different values of other parameters (pressure, speed and height of the granules layer) is shown. An increase in the friction coefficient from speed and decrease from pressure, as well as the absence of dependence on the height of the layer of granules at a certain temperature are proved.

5. The dependence of the reduced friction coefficient of granular polyvinyl chloride on the steel surface on the height of the granules layer at different values of other parameters (pressure, speed and temperature) is determined. The practical absence of dependence of the friction coefficient on speed and on temperature, as well as a slight decrease on pressure is shown. An increase in the friction coefficient from speed and temperature, as well as a decrease from pressure at a certain height of the granules layer is proved.

6. It is established that the value of the lateral pressure coefficient increases under the following conditions: temperature increase; reduction of axial pressure; reducing the speed of the steel limiting surface; the lateral pressure coefficient does not depend on the height of the granule layer.

7. The growth of the lateral pressure coefficient is most affected by the simultaneous action of temperature and speed of the steel limiting surface (linear speed of the rotating working body of the equipment). 
The obtained results make it possible to take into account the mutual influence of the friction coefficient and of the lateral pressure coefficient (together with other physical and mechanical properties of the processed polymeric material) and design and technological parameters of the equipment (including the seeding zone of the screw extruder and the working channel of the screw feeder), and therefore in the case of development and modernization of technological and ancillary equipment for processing and treatment of granular polymers make it possible to determine the rational values of design and technological parameters of the appropriate equipment.

\section{References}

1. Balsam M., Simon C.-J. (2001), Kunststoff - der Werkstoff des 21 Jahrhunderts, Kunststoffe. 91(8), p. 46.

2. Tadmor Z., Gogos C. G. (2006), Principles of polymer processing. 2nd ed., John Wiley \& Sons, Hoboken.

3. Rauwendaal C. (2014), Polymer extrusion. 5th ed., Carl Hanser Verlag GmbH \& Co. KG, Munich, DOI: 10.3139/9781569905395

4. Vlachopoulos J., Vlachopoulos N. D. (2019), Understanding rheology and technology of polymer extrusion, Polydynamics Inc., Dundas (Canada).

5. Kostic M. M., Reifschneider L.G. (2006), Design of Extrusion Dies, Encyclopedia of Chemical Processing, pp. 633-649.

6. Reifschneider L.G., Kostic M.K., Vaddiraju S.R. (2004), Computational Design of a UProfile Die and Calibrator. ANTEC, pp. 246-250.

7. Rauwendaal C. (2010), Understanding extrusion, Hanser Publishers, Munich.

8. Yilmaz O., GunesH., Kirkkopru K. (2014), Optimization of a profile extrusion die for flow balance. Fibers and polymers, 15, pp. 753-761.

9. Vytvytskyi V.M.,Karvatskyi A.Ya., Mikulionok I.O., Sokolskyi O.L. (2020), Doslidzhennia vplyvu formy i rozmiriv polimernykh granul na yikhni trybologichni vlastyvosti, Rozvidka ta rozrobka naftovykh i gazovykh rodovyshch, 2(75), pp. 52-61, DOI: 10.31471/1993-99732020-2(75)-52-61

10. Kryzhanovskiy V.K., Burlov V.V., Panimatchenko A.D., Kryzhanovskaya Yu.V. (2005), Tekhnicheckie svoystva polimernykh materialov, Professiya, Sankt-Peterburg.

11. Pakharenko V.A., Zverlin V.G., Privalko V.P., Petrushenko Ye.F., Demchenko S.S., Gladchenko A.N. (1983), Teplofizicheckie i reologicheskie kharakteristiki $i$ koeffitsienty treniya napolnennykh termoplastov, Naukova dumka, Kyiv.

12. Spalding M. A., Hyun K. S. (1995), Coefficients of dynamic friction as a function of temperature, pressure, and speed for several polyethylene resins, Polymer engineering and science, 35(7), pp. 557-563, DOI: 10.1002/pen.760350702

13. Chowdhury M.A., Nuruzzaman D.M., Roy B.K., Samad S., Sarker R., Rezwan A.H.M. (2013), Experimental Investigation of Friction Coefficient and Wear Rate of Composite Materials Sliding Against Smooth and Rough Mild Steel Counterfaces, Tribology in Industry, 35(4), pp. 286-295

14. Strutinskiy B.V., Radionenko A.V., Ishchenko Ye.A. (2015), Tribotekhnicheskie issledovaniya polimernykh kompozitov, primenyaemych pri vosstanovlenii napravlyayushchikh stankov, Problemy tertia ta znoshuvannia, 2, pp. 4-8.

15. Ishchenko A., Radionenko A., Ischenko E. (2017), Tribotechnical research into friction surfaces based on polymeric composite materials, Eastern-European Journal of Enterprise Technologies, 6(12), pp. 12-19, DOI: 10.15587/1729-4061.2017.114367

16. Liu K., Zitzenbacher G., Laengauer M., Kneidinger C. (2014), Influence of pellet shape on the external coefficient of friction of polypropylene and on the mass flow rate of a single 
screw extruder, AIP Conference Proceedings 1593, pp. 101-105; DOI: 10.1063/1.4873743

17. Längauer M., Kneidinger C., Liu K., Zitzenbacher G. (2015), Experimental study of the influences of the pellet shape on the bulk density and the frictional behavior of polypropylene, Journal of Applied Polymer Science, 9 p, DOI: 10.1002/APP.42197

18. Vytvytskyi V.M. (2020), Obladnannia ta protsess zhyvlennia cherviachnogo ekstrudera polimernoiu syrovynoiu: Ph.D thesis, Kyiv.

19. Lianfen Shao, Xin Zhou, Hongbiao Zeng (2021), Comparison of Soil Pressure Calculating Methods Based on Terzaghi Model in Different Standards, The Open Civil Engineering Journal, 15, pp. 481-488, DOI: 10.2174/1874149501610010481

20. Widisinghe S., Sivakugan N. (2012), Vertical Stresses within Granular Materials in Silos, ANZ Conference Proceedings, pp. 590-595.

21. Das B.M. (2010), Principles of Foundation Engineering, CL Engineering.

22. Aniskin A. (2016), Experimental research on lateral pressure of granular media within closely spaced walls considering different filling conditions, Elektronički časopis građevinskog fakulteta Osijek, 13, pp. 30-38, DOI: 10.13167/2016.13.4

23. Horabik J., Rusinek R. (2002), Pressure ratio of cereal grains determined in a uniaxial compression test, International Agrophysics, 16, pp. 23-28.

24. Ming-Guang Li, Jin-Jian Chen, Jian-Hua Wang (2017), Arching effect on lateral pressure of confined granular material: numerical and theoretical analysis, Granular Matter, pp. 11-20, DOI: $10.1007 / \mathrm{s} 10035-017-0700-2$.

25. (2017), SorVyl G 2171 / 9005 11/01 1. Identification of the substan - plasticker, Available at: http://plasticker.de/recybase/docs/28551_1452502854.pdf

26. Vytvytskyi V.M.,Bardashevskyi S.V., Mikulionok I.O., Sokolskyi O.L. (2018), Doslidzhennia trybotejhnichnukh vlastyvostei granuliovanykh polimernykh materialiv, Vcheni zapysky Tavriiskogo natsionalnogo universytetu imeni V. I. Vernadskogo, 29(68(5)), part 1, pp. 9-13.

27. Makarichev Yu.A., Ivannikov Yu.N. (2016), Metody planirovaniya eksperimenta $i$ obrabotki dannykh,SGTU, Samara.

28. Radchenko L. B. (1999), Pererobka termoplastiv metodom ekstruziyi, IZMN, Kyiv.

29. Wilczyński K. A. (1996), Computer Model for Single-Screw Plasticating Extrusion, Polymer-Plastics Technology and Engineering, 35, pp. 449-477, DOI: 10.1080/03602559608000931. 